\title{
WIND ASSESSMENT FOR MICRO WIND TURBINES IN AN URBAN ENVIRONMENT
}

\author{
SIMON VAN OVEREEM, LOUIS ALEN, YAIR BROUWER, ANDRE D. VAN DAM, GLENN M. VAN \\ DEKKEN, GEOFFREY H. GARRETT, SVEN GEBOERS, JELLE A. W. POLAND, HARRY W. S. \\ ALDRIDGE, VINIT V. DIGHE \& NIKOLAOS CHRYSOCHOIDIS-ANTSOS \\ Delft University of Technology, The Netherlands.
}

\begin{abstract}
Wind flow in urban environments could be seen as a potential source of energy. This form of energy could be exploited by means of micro wind turbines placed along the existing infrastructures. To test this, an outdoor campaign was organised, which recorded the wind characteristics at different locations around a highway noise barrier in Delft, the Netherlands. The real-time data set was validated with a two-dimensional Computational Fluid Dynamics study. Both the influence of the high turbulence and the inflow angle on the positioning of the micro wind turbines are assessed for the case of perpendicular flow towards the plane of the noise barrier. Results indicated that integrating micro wind turbines with the noise barriers proves advantageous due to the flow velocity increment downstream. Lastly, a noise assessment was conducted in order to determine the optimal spacing between micro wind turbines, which impacts its social acceptance.
\end{abstract}

Keywords: CFD, noise assessment, noise barrier, urban environment, wind turbines

\section{INTRODUCTION}

The impetus to sustainability and advances in technology has shown a constant development in renewable methods for generating energy [1]. Wind energy is an inexhaustible form of energy that is already being harnessed on a large scale, both offshore and onshore [2]. Additionally, high concentrations of wind flow in urban environments could be seen as a potential form of energy [3]. Studies indicate that this unrealised form of energy could be exploited by means of micro wind turbines (MWTs) mounted on existing infrastructures, i.e. the noise barriers framework, from hereon referred to as NB. Results indicate that the NB structures lead to an increase in wind speed downstream and thus provide a viable position for the MWTs [4]. Integrating MWTs into the existing infrastructures could also reduce the overall costs involved in setting up the turbine, and provide power for local applications like street lighting and electrical vehicle charging in the future. This study investigates the integration of MWTs in the urban framework. More specifically, a wind site assessment study for wind turbine application is presented.

Accurate measuring techniques to measure turbulent wind characteristics for wind harvesting in urban environments have only recently been developed and experimented upon [4]. Insights into the possible applications of MWTs in an urban environment demand a sitespecific study, which was achievable through an outdoor measurement campaign. The assessment was further enhanced by combining the measurements with Computational Fluid Dynamics (CFD) simulations to allow the representation of the flow around the NB. A significant concern is that the turbulent nature and the inflow angle of the wind will negatively affect the efficiency of the turbine, and thereby affecting the turbine's overall performance [5].

The operation of micro wind turbines at a community level requires standardisation and social acceptance. NBs have been positioned in order to reduce noise levels near residential areas caused by vehicles and other disturbances along highways [6]. The level of noise produced by wind turbines is a contentious issue and could potentially lead to opposition from local communities. 
Therefore, a noise assessment is performed to ensure that the noise created by MWTs does not exceed the local maximum sound level, which is $41 \mathrm{~dB}$ by night and $47 \mathrm{~dB}$ during the day [7].

\section{METHODOLOGY}

The following section presents the description of the test-setup for the outdoor experimental campaign. Also, a detailed description of the CFD methodology and the empirical calculations for the reference wind turbine's performance are reported in this section.

\subsection{Campaign Site}

An outdoor measurement campaign was conducted at the intersection of the provincial road N470 and the A13 highway in Delft, the Netherlands. The test-setup was positioned on an elevated part, next to the $5.20 \mathrm{~m}$ tall NB assemblage, which is located $10 \mathrm{~m}$ away from the asphalt of the road. Eight WindMaster Pro anemometers (WM) [8] were used for the measurements, which were distributed over three poles and installed at different heights. The test-setup and a section cut are shown in Fig. 1.

The anemometers record three-dimensional wind speed data ( $\mathrm{x}-, \mathrm{y}$ - and $\mathrm{z}$-directions) and can measure wind velocities up to $65 \mathrm{~m} / \mathrm{s}$ [8]. Based on the readings, the wind direction in the horizontal plane $(\bar{\gamma}+\psi)$ and the vertical inflow angle ( $\theta)$ can be defined as shown in Fig. 2. The yaw angle $(\psi)$ is then defined as the difference between the mean wind direction for the two hour data set $(\bar{\gamma})$ and the present wind direction $(\bar{\gamma}+\psi)$.
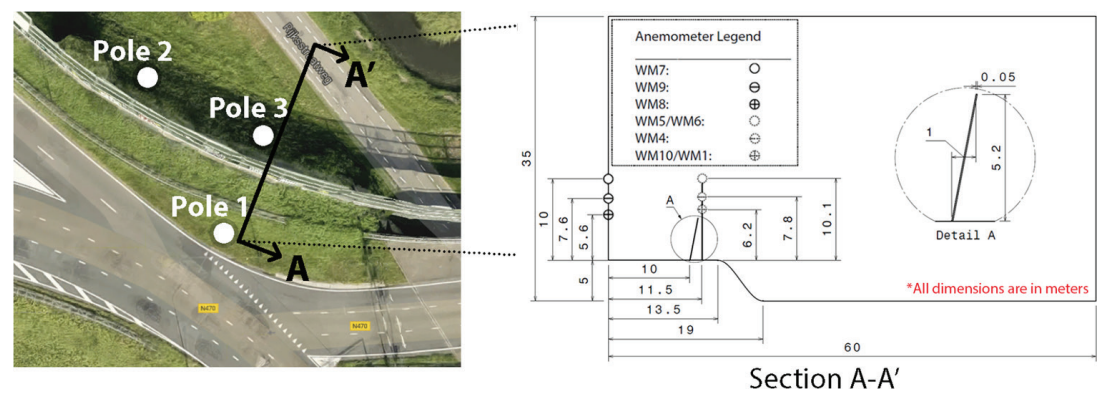

Figure 1: Aerial image of the test-setup (left) and the section cut indicating the measurements (right).

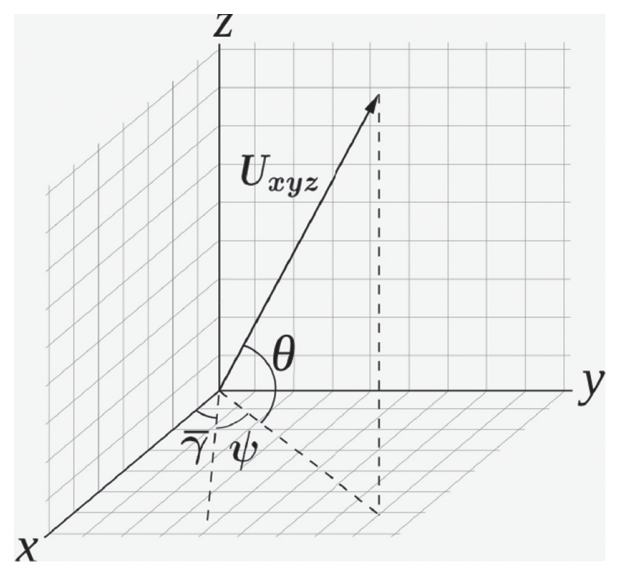

Figure 2: Coordinate system with velocity vector $\left(U_{x y z}\right)$ and relevant angles. 
The data acquired by the anemometers was collected at a sampling frequency of $4 \mathrm{~Hz}$ over a time interval of two hours. A 3-sigma outlier removal method was used such that every data point outside the range $\bar{U} \pm 3 \sigma$ was deleted, with $U$ and $\sigma$ being the mean and standard deviation of each data set, respectively. For the wind turbine performance analysis, the velocity component of interest is $U_{x y}$. For every anemometer, the $U_{x}, U_{y}$ and $U_{z}$ component were recorded and therefore the $U_{x y}$ velocity component, yaw angle and the turbulence intensity was calculated using a 10 minutes sampling period. The turbulence intensity was calculated using the $x y z$ velocity vectors.

\subsection{CFD Model}

The numerical flow is governed by the continuity and the Navier-Stokes (in the form of momentum conservation) equations (see eqn. (1) and eqn. (2)). A k- $\omega$ SST (shear stress transport) was used as a turbulence model. Preliminary investigations have shown that the model is suitable for cases involving adverse pressure gradients [9].

$$
\begin{gathered}
\frac{\partial u_{i}}{\partial x_{i}}=0 \\
\rho \frac{\partial u_{i}}{\partial t}+\rho \frac{\partial\left(u_{i} u_{j}\right)}{\partial x_{j}}=-\frac{\partial p}{\partial x_{i}}+\mu\left(\frac{\partial^{2} u_{i}}{\partial x_{j}^{2}}+\frac{\partial^{2} u_{j}}{\partial x_{j} \partial x_{i}}\right)
\end{gathered}
$$

The computational domain used for the numerical study is shown in Fig. 3. The domain is discretised using a structured mesh. Bi-geometric bunching law is applied to achieve a finer mesh near the NB geometry, and gradually coarsening as it moves further upstream and further downstream.

The convergence towards a unique numerical solution is heavily dependent on the implementation of correct boundary conditions suited to the real geometry being modelled. Velocity inlet and pressure outlet boundaries are defined to simulate the far-field flow conditions, as shown in Fig. 3. A quadratic velocity profile is described, which is obtained through the real measurements of the anemometers placed upstream of the NB. This allows a realistic flow

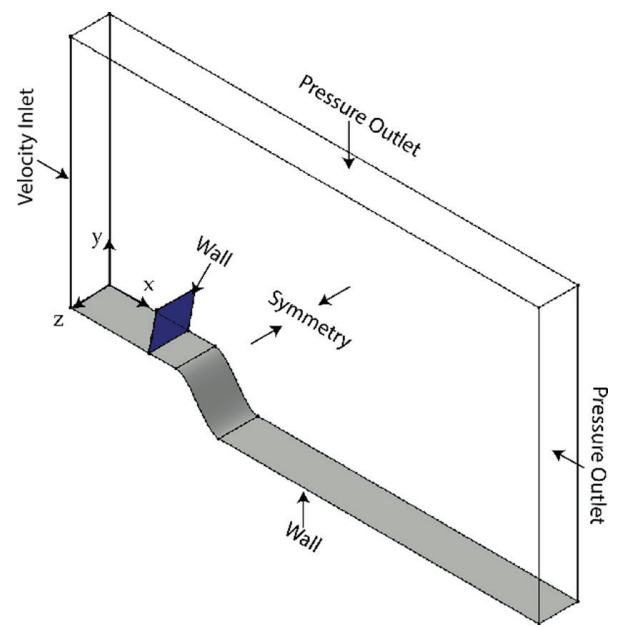

Figure 3: Flow domain designed within ANSYS ${ }^{\circledR}$ ICEM with associated boundary conditions. 
Table 1: Organisation of anemometers into Set $1 \& 2$, before and after the NB respectively.

\begin{tabular}{lllll}
\hline Set 1 & Pole 1 & WM7 & WM9 & WM8 \\
Set 2 & Pole 2 & WM1 & - & WM6 \\
& Pole 3 & WM10 & WM4 & WM5 \\
\hline
\end{tabular}

Table 2: Boundary conditions and values of the flow domain in the CFD model.

\begin{tabular}{lll}
\hline Boundary & Type & Condition \\
\hline$y z_{x=0}$ & Velocity Inlet & $\mathrm{V}=U_{x=0}(\mathrm{y})$ \\
$y z_{x=60}$ & Pressure Outlet & $\mathrm{I}=30.67 \%$ \\
$x z_{y=30}$ & & $\mathrm{I}=24.98 \%$ \\
Surfaces & Pressure Outlet & $\mathrm{P}=101325 \mathrm{~Pa}$ \\
All xy-planes & Wall & $\mathrm{I}=24.98 \%$ \\
\hline
\end{tabular}

Table 3: Mass flux distribution for the numerical solution.

\begin{tabular}{lllll}
\hline Boundary & $x z_{y=30}$ & $y z_{x=0}$ & $y z_{x=60}$ & Sum \\
Mass Flux [kg/s] & -67.657 & 142.497 & -74.839 & 1.0 \\
\hline
\end{tabular}

field initialisation and improves the solution approximation of the flow downstream, which is of primary interest. The turbulence intensity (I) is set to the average turbulence intensity for Set $1 \& 2$, which is obtained from the real measurements. The sets and their respective anemometers can be found in Table 1 . As the model generated is represented by a two-dimensional profile, the side wall boundary conditions are described by symmetry within a unit distance of one another.

The solutions of momentum, turbulent kinetic energy and specific dissipation rate were second order accurate based on upwind differential scheme. The boundary conditions used for the CFD model are displayed in Table 2.

In order to verify the completeness of the CFD solution, the mass flux of the system is calculated. Table 3 indicates the sum of the mass flux within the system. It is notable that there is $1 \mathrm{~kg} / \mathrm{s}$ of mass flow that is unaccounted for in the residuals. This is close to negligible compared to the entire mass flow of the system which indicates substantial verification of the system when consideration is placed on the relative value. Therefore, the solution is verified.

\subsection{Reference Turbine}

The reference turbine used for the analysis is a $1 \mathrm{~kW}$ MWT designed by FuturEnergy with a cut-in wind speed of $3 \mathrm{~m} / \mathrm{s}$. For the reference case, the power-velocity curve given by the manufacturer is used to compare with the deduced performance under outdoor conditions.

The power output of the wind turbine is given by eqn. (3). The power generated by a wind turbine $(P)$ is dependent on the power coefficient of the wind turbine $\left(C_{\rho}\right)$, the air density $(\rho)$, the area of the rotor $\left(A_{d}\right)$ and the free stream velocity $\left(U_{\infty}\right)[10,11]$. 


$$
P=\frac{1}{2} C_{p} \cos ^{3}(\psi) \rho \mathrm{A}_{d} U_{\infty}^{3}
$$

Note that for a yawed flow, the maximum power is proportional to $\cos ^{3}(\psi)$. The yaw angle has therefore a direct influence on the power generated [5, 12].

\subsection{Sound Assessment}

Integrating MWTs along highway NBs introduces a new source of sound, which may emit intolerable sound levels into the nearby community. Therefore an optimal spacing has to be determined to ensure that the MWTs do not exceed the allowable $41 \mathrm{~dB}$ sound level. Apart from the horizontal wind velocity, the sound level at the nearest facade also depends on the spacing $(b)$ between the MWTs on the NB as well as its distance $(d)$ to the nearest facade, as illustrated in Fig. 4. Note that every MWT will be treated as an individual sound source. A relation between the sound power produced and the maximum wind velocity was found by fitting data provided by FuturEnergy, whom have performed a noise assessment on their product [13]. This relation is given by eqn. (4), which gives the maximum sound power $\left(P_{S W}\right)$ in microwatt as function of the maximum wind velocity $\left(V_{\max }\right)$.

$$
P_{S W}=8.04 \mathrm{e}^{0.2216 V_{\max }}
$$

It is necessary to take both the sound produced by the highway traffic as well as the sound produced by the MWTs into account. The NB influences the propagation of the sound waves emitted by the highway. Explaining the working principles of a NB in depth, however, goes beyond the scope of this report. The NB lowers the sound level by a certain number (which is typically in the range of $10-40 \mathrm{~dB}[6,14])$. This number is dependent on the material transmission loss factor. By reducing the sound level, the NB effectively lowers the highway noise power which in turn reduces the noise level at the houses. For calculations a sound level of $53.5 \mathrm{~dB}$ was assumed $[6,15]$, this is at a distance of $10 \mathrm{~m}$ from the highway and includes the loss due to the NB.

Wind gusts will only give a temporary high horizontal wind velocity, therefore a 3-sigma confidence interval was used such that the maximum horizontal wind velocity that has to be taken into account is $V_{\max }=\bar{U}+3 \sigma$ With the assumption of a spherical sound distribution, using an infinite series (eqn. (5)) to calculate the contribution of each individual MWT at a point location (Fig. 4), the total sound intensity at the facade is calculated, as stated in eqn. (6).

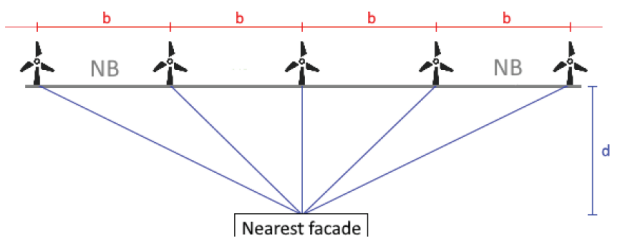

Figure 4: Spacing between the MWTs (b) and the distance of the NB to the nearest facade (d). 


$$
\begin{gathered}
\sum_{n=1}^{\infty} \frac{1}{n^{2}+a}=\frac{-1+\sqrt{a} \cdot \pi \cdot \operatorname{coth}(\sqrt{a} \cdot \pi)}{2 a} \\
I_{w}=\frac{P_{S W}}{4 \pi}\left(\frac{1}{d^{2}}+2 \cdot \sum_{n=1}^{\infty} \frac{1}{(\mathrm{n} \cdot \mathrm{b})^{2}+d^{2}}\right) \\
=\frac{P_{S W}}{4} \frac{\operatorname{coth}\left(\frac{d \cdot \pi}{b}\right)}{d \cdot b}
\end{gathered}
$$

\section{RESULTS}

This section initially introduces the mean flow properties after which the CFD model is validated. Using the results, the annual energy production for the reference turbine placed at every anemometer location height in the test-setup was calculated. Finally, results pertaining to the noise assessment and economic impact are described.

\subsection{Mean Flow Properties}

Table 4 shows the position, mean wind direction (MWD), loss due to yaw, turbulence intensity (I), mean value of the horizontal velocity component $\left(U_{x y}\right)$ and the mean value of the velocity component in the z-direction $\left(U_{z}\right)$ for each anemometer. By comparing the average loss factor due to yaw angle at different heights, it can be concluded that at a height of approximately 6 $\mathrm{m}$, the loss factor is lower behind the NB compared to the free stream. As the height increases, the loss factor behind the NB decreases, while the loss factor of the pole in the free stream (pole 1) increases. The average turbulence intensity values before and after the NB are $31 \%$ and $24 \%$, respectively. The higher turbulence intensity before the NB could be due to traffic passing by. Furthermore, it can be observed that $U_{x y}$ decreases with increasing height in the free stream, while for the poles behind the NB, it increases with increasing height. Conversely, the $U_{z}$ velocity component increases with height in the free stream, but decreases with height after the NB. Finally, a noteworthy feature result can be observed for WM10, where the mean wind direction is equal to $1.32^{\circ}$. This appears to be the result of the sample angles being placed almost perfectly symmetrical around $0^{\circ}$. This can also be concluded from the fact that its yaw loss factor is smaller than the others.

Table 4: Mean flow properties recorded for different anemometers.

\begin{tabular}{llllll}
\hline Anemometer (Pole \#) & MWD [deg] & Yaw loss [-] & $\mathbf{I}[\%]$ & $U_{x y}[\mathbf{m} / \mathbf{s}]$ & $U_{z}[\mathbf{m} / \mathbf{s}]$ \\
\hline WM 8 (1) & -12.81 & 0.82 & 34 & 3.50 & 0.33 \\
WM 9 (1) & -20.80 & 0.90 & 28 & 4.16 & 0.45 \\
WM 7 (1) & -13.00 & 0.88 & 30 & 3.86 & 0.55 \\
WM 1 (2) & -23.75 & 0.78 & 28 & 3.97 & 1.57 \\
WM 6 (2) & -22.45 & 0.92 & 25 & 5.02 & 0.92 \\
WM 10 (3) & 1.32 & 0.75 & 24 & 4.08 & 1.70 \\
WM 4 (3) & -18.74 & 0.86 & 24 & 4.41 & 1.13 \\
WM 5 (3) & -15.50 & 0.90 & 23 & 4.73 & 0.87 \\
\hline
\end{tabular}




\subsection{CFD Analysis Results}

The solution to the CFD model was considered converged after residuals fell below the order of $10^{-5}$ which provides significant accuracy regarding the discretisation, iteration and round off error in the numerical model. Figure 5 shows that the locations where the anemometers are located are not in the highest magnitude of flow potential.

Comparison of the velocity profiles before and after the NB in Fig. 6a lead to two observations. Firstly, the velocity magnitude before the NB drops closely to zero at collision with the NB. Secondly, the velocity magnitude at Set 2 shows significant increase, predominantly at a greater height.

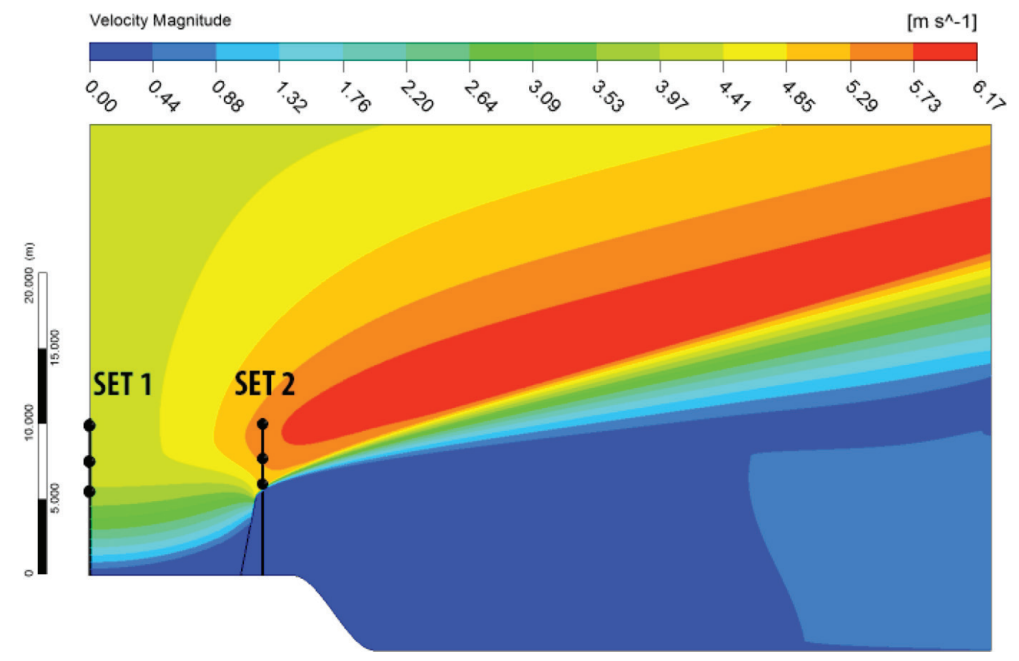

Figure 5: Velocity magnitude contours plotted using ANSYS ${ }^{\circledR}$ Fluent showing anemometer sets. The right-most red color of the legend represents the greatest magnitude in velocity and the left-most blue color, the lowest.

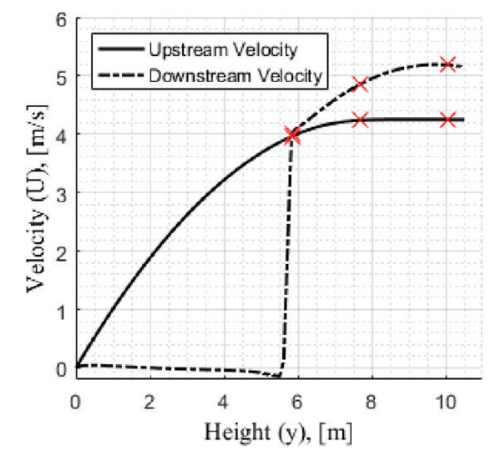

(a) Velocity profile upstream of the NB (Set 1) and downstream from the NB (Set 2). The crosses $(x)$ depict the anemometer locations through which interpolation provided the inlet velocity profile $U_{x=0}(\gamma)$.

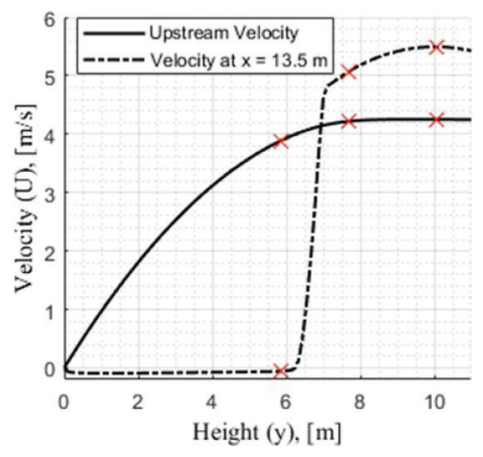

(b) Velocity profile upstream of the NB at an xcoordinate of $13.5 \mathrm{~m}$ depicting a location of greater wind velocities than that of the location of Set 2 (Pole $2 \& 3$ ). For comparative purposes, upstream velocity is shown.

Figure 6: Wind velocity analyses on the CFD model from the velocity contours in Fig. 5. The crosses $(x)$ depict the anemometer locations. 
Table 5: Absolute and model errors between the CFD analysis and the outdoor measurements.

\begin{tabular}{llcccc}
\hline & & \multicolumn{2}{c}{ Physical [m/s] } & \multicolumn{2}{c}{ Model error [\%] } \\
\cline { 3 - 6 } Location & Model [m/s] & Pole 2 & Pole 3 & Pole 2 & Pole 3 \\
\hline WM5/WM6 & 5.182 & 5.06 & 4.77 & 2.35 & 7.95 \\
WM4 & 4.893 & - & 4.43 & - & 9.46 \\
WM10/WM1 & 4.167 & 3.98 & 4.10 & 4.49 & 1.61 \\
\hline
\end{tabular}

\subsubsection{Validation of CFD Model}

Values deduced from CFD are compared to the values of Set 2 of the anemometers providing an estimation of the model uncertainty. Table 5 shows that the model errors fall below $10 \%$, wherein, the largest error occurs for WM4 at pole $3(9.46 \%)$.

With the limited amount of data points available in the data sets, the level of model error is considered reasonable.

\subsection{Potential Annual Energy Production (AEP)}

As discussed in subsection 3.1, Table 4 displays the yaw loss for every anemometer. To obtain a power curve for every anemometer that takes into account the yaw loss, the power curve provided by the manufacturer (theoretical ceiling) [11] has to be multiplied with the yaw loss. This results into a comparison power curve for every location. The one for WM6 is given in Fig. 7. Using the method of moments, a Weibull distribution for the different anemometers was plotted to obtain a probability density function $[16,17]$.

Multiplying each Weibull distribution with the corresponding power curve under yaw conditions results in a graph, which upon integration gives the expected power output. From this value, the AEP can be obtained in $\mathrm{kWh}$. Note that this annual energy estimation is still theoretical as it does not take turbulence intensity into account. If the turbulence intensity is higher than $21 \%$ on a ten minute interval, the theoretical power will be increased by $4 \%$ [18]. From subsection 3.1, it can be seen that the turbulence intensity is higher than $21 \%$ at every location, and therefore an increase in power of $4 \%$ has to be taken into account when estimating the real AEP.

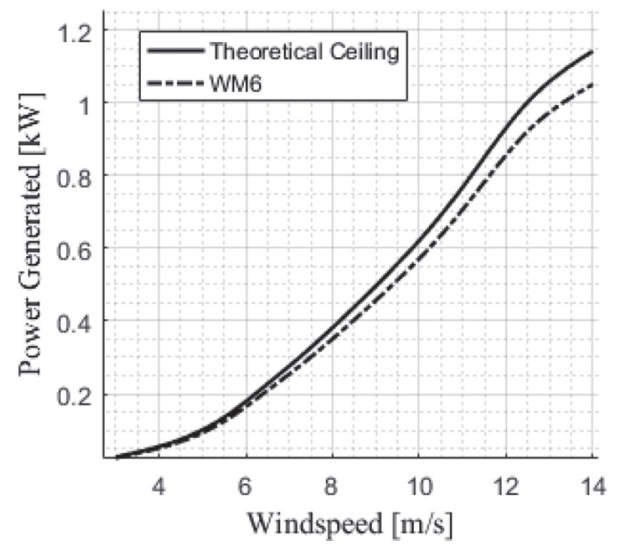

Figure 7: Power produced as a function of wind speed for the position of WM6. 
Table 6: Theoretical AEP for different anemometers.

\begin{tabular}{lllllllll}
\hline Windmaster & WM1 & WM4 & WM5 & WM6 & WM7 & WM8 & WM9 & WM10 \\
Energy [kWh] & 450.2 & 650.1 & 827.4 & 1024.1 & 458.9 & 339.2 & 588.3 & 454.2 \\
\hline
\end{tabular}

The final AEP for every anemometer location has been displayed at Table 6. It can be deduced that the produced power decreases with height for the free stream pole (pole 1). For the two poles behind the NB however, the power generated increases with increasing height. From Table 6, it can be deduced that the maximum power output occurs at the position where WM6 is located. However, from Fig. 5, it can be seen that WM6 is not the place where a maximum wind velocity occurs. A maximum wind velocity of $6.2 \mathrm{~m} / \mathrm{s}$ can be obtained $22 \mathrm{~m}$ behind the noise barrier. Using this mean velocity, a resulting AEP of $1553.1 \mathrm{kWh}$ was found.

\subsection{Socio-Economic Impact}

The socio-economic impact will first give the effects on the sound level due to the MWTs. Not only the sound level is an important concern, but also the feasibility of the implementation of MWTs. Therefore, the economic perspective of integrating MWTs in the urban framework will be considered.

\subsubsection{Sound Assessment}

From subsection 2.4, a horizontal wind velocity of $9.25 \mathrm{~m} / \mathrm{s}$ was found for WM6. Using eqn. (4), this results in a turbine sound power of $0.0625 \mathrm{~mW}$. Furthermore, the sound power of the highway can be calculated to be $0.2813 \mathrm{~mW}$. The total intensity can then be calculated by adding the sound intensity due to the MWT $\left(I_{W}\right)$ and the sound intensity due to the highway $\left(I_{H}\right)$. Given a horizontal wind velocity of $9.25 \mathrm{~m} / \mathrm{s}$, a contour plot of the sound level based on the spacing of the wind turbines and the distance to the NB can be produced. The contour plot is shown in Fig. 8.

For the test location in Delft, the distance to the nearest facade is $40 \mathrm{~m}$. This results in a minimal spacing of $100 \mathrm{~m}$ to stay under the noise level limit. If the spacing is lower than this minimal spacing, the allowed noise level is surpassed.

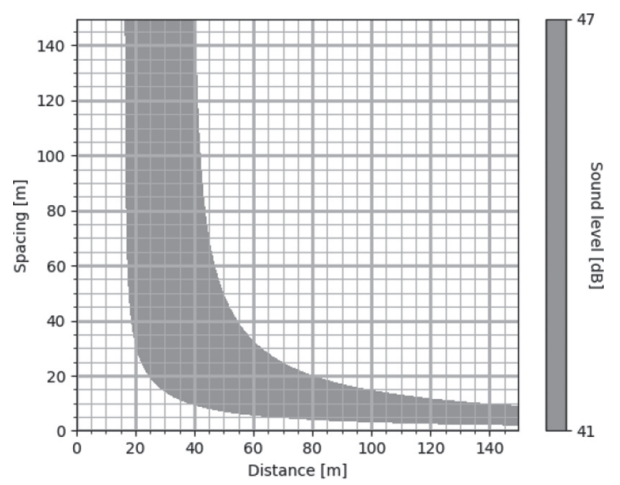

Figure 8: Contour plot providing sound levels, levels of interest (47 dB (left) and $41 \mathrm{~dB}$ (right)) are accentuated. Sound levels are in function of the spacing $\mathrm{b}$ and the distance $\mathrm{d}$. 


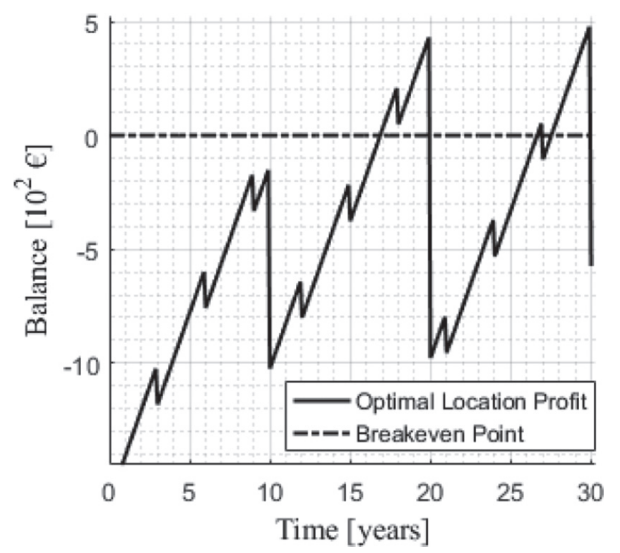

Figure 9: Operating income generated incorporating maintenance costs per MWT (in EUR).

\subsubsection{Economic Impact}

In order to make the installation of MWTs an economically viable plan, it needs to be confirmed that the power produced by these micro wind turbines generates sufficient income to amortise the purchase and maintenance costs of the MWTs. To visualise the economic benefit of the MWTs, Fig. 9 shows the operating income of the MWTs as a function of time. Note that this is calculated for the best-case scenario, where the MWTs are placed at a region of maximum velocity obtained from the CFD model, being $6.2 \mathrm{~m} / \mathrm{s}$, at a distance of $22 \mathrm{~m}$ from the noise barrier (see Fig. 5).

The assumption is made that the energy produced can be directly used, saving the costs of buying electricity at the price of $0.18190 \mathrm{EUR} / \mathrm{kWh}$, while estimated electricity network costs (to put electricity on the net) are 0.061 EUR/kWh [19]. The FuturEnergy $1 \mathrm{~kW}$ MWT currently costs 1200 GBP (circa 1428 EUR at present). According to article 3.14 of the Dutch civil code for environment, all forms of wind energy devices need a performance and maintenance check at least once a year [7]. Thus, after this initial purchase cost, about every three years a total maintenance cost of 150 GBP (circa 178 EUR) can be expected [20]. Within the range of ten years, the inverter of a MWT also needs replacement, which has a cost estimated to be 750 GBP (circa 893 EUR). At the end of its lifespan, about 20 years, the MWTs have to be replaced [21]. It can be seen that the turbine starts to generate a net revenue after 17 years. Note that the costs are taken very conservatively.

\section{CONCLUSION}

From the analysis of the data set, it can be concluded that the best position for placing a micro wind turbine (MWT) is at a height of $10 \mathrm{~m}$ downstream of the noise barrier (NB), which corresponds to WindMaster 6 . At this position, the annual energy production (AEP) of the MWT is estimated to be $1024.08 \mathrm{kWh}$. However, further downstream of the NB assemblage a region of even greater flow potential is obtained. This is done using the validated Computational Fluid Dynamics (CFD) model. The AEP at this position will then be $1553.1 \mathrm{kWh}$. It is therefore apparent that the optimal position for placing a MWT will be within this region.

As NBs are primarily designed to reduce the noise emitted by highway traffic, adding another source of sound (the MWT) on top of the NBs is not beneficial. Using data provided by the manufacturer and the data set obtained from the measurements, a minimum spacing of 
$100 \mathrm{~m}$ between two MWTs was found to ensure that the legal sound limit of $41 \mathrm{~dB}$ will not be surpassed at the nearest house. Regarding economic sustainability, the current estimations for power output at the optimal location according to the CFD model outweigh the cost estimates for the turbine upkeep and maintenance cost provided by the manufacturer after 17 years. Note that these costs are taken conservatively. The wind turbine would generate revenue sooner, especially when MWTs are deployed on a large scale. Ultimately, this report has demonstrated that the flow over a NB increases its velocity, which in turn increases the power output of a MWT placed behind it. The research has shown that the implementation of MWTs in an urban environment is a feasible future energy solution.

\section{RECOMMENDATIONS}

With the goal to further improve on this research, a few additions that were considered to be added to this article will be listed in this section. These considerations were beyond the scope of the original question answered and could therefore lead to potential topics for further research.

The effect of the vertical inflow angle on the MWT's performance was ignored. The vertical inflow angle and the wind directivity will realistically cause a fluctuation in the energy output of the MWT; the significance of the performance fluctuation could be investigated by using a 3D CFD model over the currently used 2D CFD model.

Furthermore, the cost analysis performed in this study was executed using conservative values for maintenance and inverter replacements. One could consider doing an experiment in which a MWT is placed in similar conditions and record the costs that are required for one MWT in operating conditions throughout one year. A detailed cost assessment of various aspects involved would give a better view on the economical viability.

Finally, in this study, only two hours of measurements were taken due to facility limitations. By using longer measurements throughout the year, it is possible to include measurements through all weather conditions. Generating an annual energy production based on data recorded over the span of an entire year, would allow for better insight into the effectiveness and feasibility of MWTs in an urban environment.

\section{REFERENCES}

[1] Dincer, I., Renewable energy and sustainable development: a crucial review. Renewable and Sustainable Energy Reviews, 4, pp. 157-175, 2000. https://doi.org/10.1016/s1364-0321(99)00011-8

[2] Tong, W., Wind Power Generation and Wind Turbine Design, WIT Transactions on State-of-the-art in Science and Engineering, vol. 44, WIT Press: Southampton and Boston, p. 20, 2010.

[3] Britter, R.E. \& Hanna, S.R., Flow and dispersion in urban areas. Annual Review of Fluid Mechanics, 35, pp. 469-496, 2003. https://doi.org/10.1146/annurev.fluid.35.101101.161147

[4] Abohela, I., Neveen, H. \& Dudek, S. Effect of roof shape, wind direction, building height and urban configuration on the energy yield and positioning of roof mounted wind turbines. Renewable Energy, 50, pp. 1106-1118 2013.

https://doi.org/10.1016/j.renene.2012.08.068

[5] Burton, T., Sharpe, D., Jenkins, N. \& Bossanyi, E., Wind Energy Handbook, John Wiley \& Sons, Chichester, 2001.

[6] Environmental Protection Department Highways Department. Guidelines on Design of Noise Barriers, pp. 4-5, 2003. 
[7] Dutch Government. Wet- en regelgeving (in Dutch), available from: http:// www.wetten.overheid.nl/BWBR0022762/2017-02-02\#Hoofdstuk3_Afdeling32_323 (Accessed on: 31 April 2017).

[8] Gill Instruments Limited. Windmaster Pro 3-Axis Anemometer, available at: http:// www.gillinstruments.com/products/anemometer/windmaster- pro.html. (Accessed on: 24 April 2017).

[9] Dighe, V.V., Avallone, F., Tang, J. \& van Bussel, G.J.W., Effects of Gurney Flap on the performance of Diffuser Augmented Wind Turbines. 35th Wind Energy Symposium, American Institute of Aeronautics and Astronautics, p. 3, 2017.

[10] Accon-UK. FuturEnergy: Turbine to scale drawing, available at: http://www.futurenergy.co.uk/pdf_doc/Airforce1TurbinetoScaleDrawing.pdf. (Accessed on 3 May 2017).

[11] Accon-UK. FuturEnergy: $24 \mathrm{~V}$ wind turbine power curve, available at: http:// www.futurenergy.co.uk/pdf_doc/24VTurbineSpec\&PowerCurve.pdf. (Accessed on: 3 May 2017).

[12] Ozbay, A., Tian, W., Yang, Z. \& Hu, H. Interference of Wind Turbines with Different Yaw Angles of the Upstream Wind Turbine, 42nd AIAA Fluid Dynamics Conference and Exhibit, American Institute for Aeronautics and Astronautics, p. 2719, 2012.

[13] Accon-UK. FuturEnergy: 1kW Airforce Wind Turbine Noise Assessment, available at: http://www.futurenergy.co.uk/pdf_doc/Airforce1NoiseAssessment.pdf. (Accessed on: 27 March 2017).

[14] Vargas, C., Understanding the basics of sound control, April 2007.

[15] Sengpielaudio. Table of sound levels L (loudness of noise) with corresponding sound pressure and sound intensity, available at: http://www.sengpielaudio.com/TableOfSoundPressureLevels.htm. (Accessed on: 28 April 2017).

[16] The Wind Power Program. Wind statistics and the Weibull distribution, available at: http://www.wind-power-program.com/wind_statistics.htm. (Accessed on: 3 May 2017).

[17] Justus, C., Hargraves, W., Mikhail, A. \& Graber, D. Methods for estimating wind speed frequency distributions. Journal of Applied Meteorology, 17, pp. 350-353, 1978. https://doi.org/10.1175/1520-0450(1978)017<0350:mfewsf>2.0.co;2

[18] Lubitz, W.D., Impact of ambient turbulence on performance of a small wind turbine. Renewable Energy, 61, pp. 69-73, 2014. https://doi.org/10.1016/j.renene.2012.08.015

[19] U.S. Energy Information Administration. Levelized Cost and Levelized Avoided Cost of New Generation Resources in the Annual Energy Outlook 2017, April 2017.

[20] Energy Saving Trust. Wind Turbines, available at: http://www.energysavingtrust.org. uk/renewable-energy/electricity/wind-turbines. (Accessed on: 1 May 2017).

[21] Accon-UK. FuturEnergy: 1kW Upwind Turbine, available at: http://www.futurenergy. co.uk/turbine.html. (Accessed on: 24 April 2017). 